\title{
Substantial Dynamics of Lymphomatous Transformation from Low-Grade to High-Grade Performance
}

\author{
Lawrence M Agius* \\ Department of Pathology, Mater Dei Hospital, Malta
}

Submission: July 30, 2018; Published: September 06, 2018

"Correspondence Address: Lawrence M Agius, Formely Department of Pathology, Mater Dei Hospital, TAL-QROQQ, University Of Malta Medical School, 27 Ballarat, Guzeppe Caruana Street, Tal-Virtu, Rabat, Rbt09Malta, Europe, Tel: 356-21451752;

Email: lawrence.agius@um.edu.mt

\section{Abstract}

Performance-dependence is origin-cell dynamics in pre-determination in the overall characterization of the transition and transitions of lowgrade to high-grade lymphomatous lesions.The subsequent outline performance of indices of biologic determination includes the proliferation attribute for performance as characterized by systems of inclusion or exclusion, as indeed formulated by the outline delivery for further evolutionary systems of re-characterization.The significant determinants of hyper-mutation and activation-performance of class-switching allow for contrast with the systemization of dynamics of performance within the specific attributes of a global performance as applicable to predeterminants.The formulation of lymphomas is hence a concern in subsequent characterization of multiple dimensions.

\section{Introduction}

The cell of origin in lymphomas in general revolves around encompassed normal lymphocyte development in terms that further conform to the dimensions for further cellular differentiation on the one hand, and of the substantial re-interpretation of migratory potentiality for further dedifferentiation and aberrant development. To account for the excess cancer rate in males, several candidates of "escape from X-inactivation tumor-suppressor" have been recently identified [1].It is further to such considerations that the individual lymphocyte is evolving re-constitution of the cellular subtype characterization and repeated re-characterization as determined in particular by the reconstitution of migratory potential for further dimensionalized re-interpretation of subtype and sub-family reformation. Angelica gigs Sakai, an oriental traditional medicine, and its major component decursin, target Myc to suppress lymphomagenesis [2].

De-suppression and re-constitutional attempts are therefore mechanistic steps in the overall aberrant performance of Ig immunoglobulin gene characterization as dictated especially by viral infection in many cases by the Epstein-Barr virus in Burkitt's lymphoma.Sub clonal mutation selection in mouse lymphoma genesis identifies known cancer loci and implicates novel candidates [3]. Plasma EBV-load can be employed as biomarker and as prognostic factor in HIV-related lymphomas [4].
Low-density lipoprotein receptor-related protein-associated protein 1 is a frequent proliferation-inducing antigen of B-cell receptors of mantle cell lymphomas and can be utilized for specific therapeutic targeting [5].Determination of sub-typing and prognostic indices for advancement in type evolution is hence the constitutional re-appraisal of such dimensions as well-projected by systems of performance-dependence in reconstitution of sub-family and cell-of-origin pre-determination. Gene expression profiling studies have identified distinct molecular signatures for accurate diagnosis and elucidation of oncogenic pathways enriched with major peripheral $\mathrm{T}$ cell lymphoma entities; also, genomic characterization has identified recurrent somatic mutations and potential therapeutic targets [6].

\section{Constitutional Determinism}

The constitutive re-affirmation of attributes of consequence revolves within the system formulations of novel indices as dysregulatory translocations and point mutations in promoter sequences, as well-borne out by the evolving sub-type reconstitution. The determinations in variance predetermination are simplified profile reactivity as terms of antigen-affinity as further projected by activated hypermutation and as constitutive further evolution in the overall global systems of lymphomagenesis.Fibroblasts are implicated in the role of microenvironment in HTLV-1-mediated lymphoma genesis [7]. 


\section{Cancer Therapy \& Oncology International Journal}

Recurrent activating mutations in members of the JAK/STAT pathway have recently been reported in enteropathy-associated T-cell lymphoma and refractory celiac disease II, which is suggestive of deregulation of cytokine signaling as an early event in lymphomagenesis [8].

The human pegivirus, classified in the Flaviviridae familyPegivirus genus, shows high prevalence of infection in nonHodgkin's lymphoma compared to controls and patients with other hematologic diseases [9].The constitutive representations for lymphomas are overall re-characterization in the face of conflicting dimensions for differentiation that evolves within a context of insufficient dedifferentiation on the one hand, and of consequential substantiation as replacement of germinal centers that are promulgated in identification and representation. Epstein-Barr virus, which is associated with B-cell proliferative disorders, also transforms T- or natural killer-lineage cells and has been associated with various T- or NK-cell malignancies such as extra nodal NK/T-cell lymphoma nasal type and aggressive NK-cell leukaemia [10]. Viral latent gene products contribute to EBV-mediated B cell transformation and probably contribute to lymphomagenesis and epithelial carcinogenesis [11].

Resetting of dimensional reconstitution is hence an over-riding pre-determination as well performed and redetermined by conversion of a follicular lymphoma to a poorprognosis characterization by diffuse forms of non-Hodgkin's lymphoma. This occurs as an integral reformulation in the face of a high degree of heterogeneity as presented by diffuse poor differentiation of many end-stage non-Hodgkin entities. Human $\mathrm{CD} 30+\mathrm{B}$ cells constitute a unique subset related to Hodgkin lymphoma cells [12].CDCA7 is a critical mediator of lymphoma genesis that selectively regulates anchorage-independent growth [13].

\section{Performance Attributes}

The performance attributes further re-constituted as poor prognosis in aggressive B- and T-cell lymphomas are simple to complex re-affirmation of the antigen-antibody systems or as post-thymic redevelopment of these specialized subtypes of lymphoma.The systematization of overall characterization is the further specialization within the formulas for further determination. An histone deacetylase 6-HR23B-MET axis appears present and HDAC6 is a potent promoter of lymphoma genesis in diffuse large B-cell lymphoma. Thus, a therapeutic strategy utilizing HDAC6 inhibitors in combination with hepatocyte growth factor receptor MET inhibitors is promising [14].

Hence, concepts of pre-determination as affirmed by cell-oforigin systems allow for the heterogeneous re-systematization of performance attributes as simple to complex affirmation of new or novel indices of performance derivation of individual and clonal sub-populations of the lymphoma cells.Compared with the catalytic subunits, the core subunits, including DPY30, of the major H3K4 methyltransferase complexes are frequently amplified in human cancers and selectively unregulated in Burkitt lymphoma; hijacking a key chromatin modulator creates epigenetic vulnerability for MYC-driven cancer [15]. The performance indices are based especially on the constitution of outline profile shifts in re-characterized antigen-antibody binding in B-cell lymphomas in general.

The prerogative determined systematization is further dimensionalized as performance-dependent system connotations as well-represented by cellular differentiation formulas. Close cellular interactions between endogenous clonal neoplastic B cells and related aberrant myeloid precursor cells/ macrophages appear to be important interactive components of aggressive non-Hodgkin lymphoma-B [16].

Re-population dynamics is a performance-dependent recharacterization as further projected especially by B-cell profile affirmation.Clearly appreciated is the pre-determination of biologic indices of contrasting poor-prognosis and indolent definition of the various phenotypic indices for further spread and re-constitution. The significant outline formulas are wellconstituted as super-imposed systems for overall definition of the performance-dependence as simple re-population of whole sub-sets of phenotypic attributes.The impact of continuing rheumatoid arthritis activity and immune stimulation appears to be the most significant in lymphoma genesis in these patients [17].

\section{Re-Definition of Differentiation}

An overall index re-definition of axial prototypes in differentiation encompasses the performance of clones of lymphomatous cells that promote the profile systems for further differentiation or de-differentiation.The contributory profiles of characterization are the overall systematization of the antigenantibody formulas of performance that are well-characterized by B-cell re-affirmation of evolutionary traits.

The pre-determination connotations are the specific profile evolutions for further re-characterization of potential profile re-setting as exemplified by activation class switching.It is further to clonal re-presentation that the profile formula of the individual lymphoma cell is advanced towards re-population of indices of activity as cell-proliferation and homing dynamics of such systems as Mantle-cell lymphomas.

There is an increasing need for better tools to risk-stratify patients with follicular lymphoma to identify those likely to experience relapse early [18].

Early and late profile outlines include the viral reconstitution of the progression clinical performance of systems of activation- and performance attributes of pathway evolution. Activation of the PI3K/AKT pathway has been implicated in Burkitt lymphoma genesis and increased PI3K/AKT activation has been associated with worse outcomes in adults with aggressive B-cell non-Hodgkin lymphoma [19]. The significant pre-determinants are overt dimensions that conceptually 


\section{Cancer Therapy \& Oncology International Journal}

re-affirm the dependence of existing clones for subsequent characterization.Whole clonal performance thus contrasts with the heterogeneity of lymphoma lesions in terms of system reinstituted profiles.Circulating saturated and monounsaturated fatty acids appear associated with risk for non-Hodgkin lymphoma [20].The significant interpretation of low-grade versus high-grade lesions is substantiated as portrayed by the performance-dependence of whole integral clones for further differentiation or de-differentiation.

\section{Peripheral Tissue Participation}

Mucosa-associated MALT lesions are response elements in the reactive re-definition of system pathways that outline the attributes of cell clones in a strictly peripheral performance, as further projected by constitutive systems of performance.Index outlining is a performance attribute for the significant predetermination that categorizes the cell proliferation that, in turn, includes differentiation of substantial performance denotations. Tumor microenvironment has progressively emerged as a central determinant of early lymphomagenesis, sub-clonal evolution, drug resistance, and late progression/transformation [21]. The overall inclusion of such indices is significant re-formulation as well-characterized systems of overall performance.

\section{Conclusion}

Performance characterization is a relative dimension that oscillates between systems of clinical and biologic determinants as constituted by cell proliferation and differentiation attributes within the acquired pre-determination of dynamic forces of celltransfer, and as well-constituted by the individual lymphoma cell and by whole integral groups of clonal subpopulations of lymphomatous cells.

It is as included dimensions for further progression that the simple repetition of turnover of lymphomatous cells further propagates as anti-apoptosis and as performance-defining terms at reconstitution.A viral protein kinase can promote B cell activation and proliferation, as well as augmenting lymphoma genesis in vivo and may therefore contribute to the development of viral cancers [22]. The overall conglomerate performance is generalized or global outline pre-determination as projected by specific site of origin and as focus selection in the further spread to lymphnodes or peripheral tissues.Defects in DNA repair pathways are selected events in cancer and lymphomas; ATM deficiency is associated with PARP1- and DNA-PKcs inhibitor sensitivity in vitro and in vivo [23]. Hodgkin's disease is reactive parameter within an integral field for further spread and evolution to high-grade lymphoma lesions.The external microenvironment is source-determination that is specific occurrence of subtle re-arrangement as well-characterized by performance dynamics.

Re-affirmation of differentiation / de-differentiaton specialized subsets concur with the significant clonal reappraisal of performance indices within category identification of low-grade transformation to high-grade lymphomatous states.Index significance is by-product determinant in overall categorization, as well-projected by systems of performancedependence.It is within such systems of performance that conceptual characterization of low-grade to high-grade lesions permits the emergence for evolutionary and pre-set determinants in oncogenic definition.

\section{References}

1. Li X, Zhang Y, Zheng L, Liu M, Chen CD, et al. (2018) UTX is an escape from X-inactivation tumor-suppressor in B cell lymphoma. Nat Commun 9(1): 2720.

2. Kim E, Nam J, Chang W, Zuffugarov IS, Okhlopkova ZM, et al. (2018) Angelica gigas Nakai and decursin downregulate Myc expression to promote cell death in B-cell lymphoma. Sci Rep 8(1): 10590.

3. Webster P, Dawes JC, Dewchand H, Takacs K, Iadarola B, et al. (2018) Suclonal mutation selection in mouse lymphoma genesis identifies known cancer loci and suggests novel candidates. Nat Commun 9(1): 2649.

4. Muncunill J, Baptista MJ, Hermandez-Rodriguez A, Dalmau J, Garcia O, et al. (2018) Plasma EBV-load as an early biomarker and prognostic factor of HIV-related lymphomas. Clin Infect Dis.

5. Thurner L, Hartmann S, Fadle, Kemele M, Bock T, et al. (2018) LRPAP1 is a frequent proliferation-inducing antigen of BCRs of mantle cell lymphomas and can be used for specific therapeutic targeting. Leukemia.

6. Lone W, Alkhiniji A, Manikkam Umakanthan J, Iqbal J (2018) Molecular insights into pathogenesis of peripheral $\mathrm{T}$ cell lymphoma: a review. Curr Hematol Malig Rep 13(4): 318-328.

7. Vicario M, Mattiolo A, Montini B, Piano MA, Cavallari I, et al. (2018) A preclinical model for the ATLL lymphoma subtitle with insights into the role of microenvironment in HTLV-1-mediated lymphoma genesis. Front Microbial 9: 1215.

8. Chander U, Leeman-Neill RJ, Bhagat G (2018) Pathogenesis of enteropathy-associated $\mathrm{T}$ cell lymphoma. Curr Hematol Malig Rep 13(4): 308-317.

9. Arroyive-Ospina JC, Caicedo MF, Navas MC, Cortex-Mancera FM (2018) Human Pegivirus: pathogenic potential and non-Hodgkin lymphoma development risk. Rev Chilean Infectol 35(2): 164-175.

10. Kimura H (2018) EBV in T-/NK-cell tumorigenesis. Adv Exp Med Biol 1045: 459-475.

11. Kanda T (2018) EBV-encoded latent genes. Adv Exp Med Biol 1045: 377-394.

12. Weniger MA, Tiacci E, Schneider S, Arnolds J, Ruschenbaum S, et al. (2018) CD+ B cells represent a unique subset related to Hodgkin lymphoma cells. J Clin Invest 128(7): 2996-3007.

13. Jimenez PR, Martin Cortazar C, Kourani O, Chiodo Y, Cordoba R, et al. (2018) CDCA7 is a critical mediator of lymphoma genesis that selectively regulates anchorage-independent growth. Haematologica.

14. Liu Z, Cai Y, Yang Y, Li A, Bi R, et al. (2018) Activation of MET signaling by HDAC6 offers a rationale for a novel ricolinostat and crizotinib combinatorial therapeutic strategy in diffuse large B-cell lymphoma" J Pathol.

15. Yang Z, Shah K, Busby T, Giles K, Khodadad-Jamayran A, et al. (2018) Hijacking a key chromatin modulator creates epigenetic vulnerability for MYC-driven cancer. J Clin Invest 128(8): 3605-3618.

16. Pham LV, Pogue E, Ford RJ (2018) The role of macrophage/B-cell interactions in the pathophysiology of B-cell lymphomas. Front Oncol 8: 147. 


\section{Cancer Therapy \& Oncology International Journal}

17. Klein A, Pollack A, Gafter-Gvili A (2018) Rheumatoid arthritis and lymphoma: incidence, pathogenesis, biology, and outcome. Hematol Oncol.

18. Becnel MR, Nastoupil LJ (2018) Follicular Lymphoma: past, present, and future. Curr Treat Options Oncol 19(7): 32.

19. Batti M, Ippolito T, Mavis C, Gu J, Cairo MS, et al. (2018) Pre-clinical activity of targeting the PI3K/Akt/mTOR pathway in Burkitt lymphoma. Oncotarget 9(31): 21820-21830.

20. Chiu YH, Bertrand KA, Zhang S, Laden F, Epstein MM, et al. (2018) A prospective analysis of circulating saturated and monounsaturated fatty acids and risk of non-Hodgkin lymphoma. Int J Cancer.
21. Verdiere L, Moucin F, Tarte K (2018) Microenvironment signaling driving lymphoma genesis" Curr Opin Hematol 25(4): 335-345.

22. Anders PM, Montgomery ND, Montgomery SA, Bhatt AP, Dither DP, et al. (2018) Human herpesvirus-encoded kinase induces B cell lymphomas in vivo. J Clin Invest 128(6): 2519-2534.

23. Knittel Gm Rehkamper T, Nieper P, Schmitt A, Flumann R, Reinhardt HC (2018) DNA damage pathways and B-cell lymphoma genesis. Curr Opin Hematol 25(4): 315-322.

\section{Your next submission with Juniper Publishers will reach you the below assets}

- Quality Editorial service

- Swift Peer Review

- Reprints availability

- E-prints Service

- Manuscript Podcast for convenient understanding

- Global attainment for your research

- Manuscript accessibility in different formats

( Pdf, E-pub, Full Text, Audio)

- Unceasing customer service

Track the below URL for one-step submission https://juniperpublishers.com/online-submission.php 